\title{
After The Diagnosis Of Cancer Long-Term Follow-Up, Psychiatric Problems And Psychotherapeutic Approaches: A Case Report
}

\section{Kanser Tanısı Sonrası Uzun Süreli İzlem, Psikiyatrik Sorunlar Ve Psikoterapötik Yaklaşım: Olgu Sunumu}

\author{
Nagihan Saday Duman ${ }^{1}$, Emel Sarı Gökten ${ }^{1}$, Ayșegül Efe $^{2}$ \\ ${ }^{1}$ Bursa Şevket Yılmaz Eğitim Ve Araştırma Hastanesi,çocuk Ve Ergen Ruh Sağlığı Birimi \\ ${ }^{2}$ Ankara Üniversitesi Tıp Fakültesi, Çocuk Ve Ergen Ruh Sağlığı Ana Bilim Dalı
}

Dergiye Ulaşma Tarihi: 26//03/2015 Dergiye Kabul Tarihi: 13/04/2015 Doi: 10.5505/aot.2015.44227

\section{ÖZET}

Kanser hastalığı olan çocukların uzun süreli izleminde bilişsel, duygusal ve sosyal alanda sorunlar yaşanmaktadır. Kanser tanısı konulan çocuklarda depresyon, posttravmatik stres bozukluğu ve somatizasyon bozukluğu gibi önemli ruhsal hastalıklara sık rastlanmaktadır. Bu olgu sunumunda Ewing Sarkomu tanısından sonra uzun bir tedavi süreci geçiren ve kanser sekeli sonucu yaşadığı psikiyatrik sorunlar için kliniğimize başvuran 16 yaşında bir ergenin izleminde uygulanan destekleyici psikoterapötik yaklaşımlar ve sonuçları tartışılmıştır.

Anahtar Kelimeler: kanser, psikiyatrik sorunlar, uzun süreli izlem, psikoterapötik yaklaşım

\begin{abstract}
Cognitive, emotional and social problems are being experienced to long-term follow up of children with cancer. Children diagnosed with cancer are frequently suffered from major mental illnesses such as depression, posttraumatic stress disorder and somatization disorder. This paper reports, in substantial details, a 16-year-old female adolescent case who had exposed to a long time period of medical treatment after the diagnosis of Ewing's Sarcoma and was admitted to our clinic for psychiatric symptoms related to sequelae of cancer. In this manuscript we discussed supportive psychotherapeutic approaches implemented to this adolescent and its follow-up therapeutic results.
\end{abstract}

Key words: cancer, psychiatric problems, long-term follow-up, psychotherapeutic approach

\section{Giriş}

Kanser tüm dünya'da önemli bir sağlik sorunudur ve yaygınlığı her geçen gün artmaktadır. Dünya Sağlık Örgütü'nün (DSÖ) verilerine göre 2008 y1lında dünya'da 12.412.7 milyon arasinda yeni kanser vakas1 bildirilmiştir (1). Son 30-40 y1l içerisinde çocukluk çağı kanserleri ölümcül olmaktan çıkıp kronik hastalıklar haline gelmeye başlamış ve günümüzde bu oran \%75-80'e kadar yükselmiştir (2). Sağ kalım oranlarının artması ile birlikte çocukların hastalık öncesinde bıraktıkları yaşamlarına geri dönmelerinin sağlanması ve hastalık sürecinde değişen aile içi rol ve işlevlerin yeniden düzenlenmesi gibi sorunlar ortaya çıkmaktadır (3).

Kanser hastalığı olan çocukların uzun süreli izleminde bilişsel, duygusal ve sosyal alanda sorunlar yaşanmaktadır (4). $\mathrm{Bu}$ çocuklarda depresyon, posttravmatik stres bozukluğu ve somatizasyon bozukluğu gibi önemli ruhsal hastalıklara s1k rastlanmaktadır. Ayrıca davranış ve uyum sorunları, benlik değerinde düşüklük ve beden imajı ile ilgili sorunlar da diğer önemli güçlüklerdir (5).

Kanser hastalığının tedavisi ve tedavi sonrası dönem süresince çocuk ve gençlerde ortaya çıkabilecek duygusal ve davranışsal problemleri belirlemek, psikiyatrik tanı alan vakaları uygun şekilde tedavi etmek, eşik altı belirtileri olanları ise yakından izleyip, destekleyici psikoterapötik yaklaşımlardan faydalanmalarını sağlamak gerekmektedir (6).

$\mathrm{Bu}$ yazida Ewing Sarkomu tanisindan sonra uzun bir tedavi süreci geçiren ve kanser sekeli sonucu yaşadığı psikiyatrik sorunlar ile kliniğimize başvuran bir ergenin izleminde

Adressforcorrespondence: Uzm. Dr. Nagihan Saday Duman. Bursa Şevket Yılmaz Eğitim ve Araştırma Hastanesi, Çocuk ve Ergen Ruh Sağlğı Birimi 06590 Bursa - Türkiye 
uygulanan destekleyici psikoterapötik yaklaşımlar ve sonuçları tartışılacaktır.

\section{Olgu:}

S, 16 yaşında, kız, lise 2. sınıf öğrencisi. Kliniğimize ağlama krizleri, nefes alamama, çarpıntı ve terleme yakınmaları ile başvurdu. Ayrıca son 3 aydır okula gitmek istememe, evden dışarı çıkmama, kendini sosyal ortamlardan izole etme yakınmaları da eşlik ediyordu.

\section{Özgeçmiş:}

$\mathrm{S}$, planlı bir gebelik sonras1 spontan vajinal yolla, zamanında doğmuş. Dokuz ay anne sütü almış, yürümeye ve konuşmaya 1 yaşında başlamış, 1.5 yaşında tuvalet eğitimini tamamlamış. 9 yaşına kadar herhangi bir sağlık sorunu olmamış. İlkokul 4. Sinıfta sol dizinde ağrı ve şişlik yakınması başlamış. O dönemde yapılan tetkikler sonucunda Ewing Sarkomu tanısı konulmuş. Tanı sonrası uzun bir tedavi süreci geçirmiş. $\mathrm{Bu}$ süreç içinde $3 \mathrm{kez}$ opere olmuş, sol femur distal ucu rezeke edilmiş. Tedavi sonunda sol bacağı diğerinden $10 \mathrm{~cm}$ daha kısa kalmıș. Başvurusundan 3 ay önce sol bacağına uzatma operasyonu yapılmış ve external fixatör takılmış. Uzun tedavi sürecinde okulundan ve arkadaşlarından uzak kalmış, arkadaşları aramadığı ve ziyaret etmedikleri için onlara kırgınlığı olmuş, arkadaş ilişkileri bozulmuş.

\section{Soygeçmiş:}

Baba: 43 yaşında, yüksekokul mezunu, teknik ressam. S, babasını ailesi ile çok ilgilenmeyen, sadece işine gidip gelen birisi olarak tanımliyor. S'in kemoterapi ve ameliyat sonrası dönemlerinde baba $\mathrm{S}$ ile hiç ilgilenmemiş, çok az ziyaret etmiş. Şu andaki ilişkilerini de mesafeli olarak tanımlıyor. Anne: 40 yaşında, üniversite mezunu, evhanımı. S, annesini sabırlı, ilgili ancak çok kaygilı ve kendisine çok düşkün birisi olarak tanımlıyor. Kardeş: 5 yaşında bir erkek kardeşi var. Kardeşini çok hareketli ve yaramaz bir çocuk olarak tanımlıyor.

\section{Ruhsal durum muayenesi:}

Yaşında gösteren, sol bacağında external fixatör olduğu için bol ve uzun kıyafetler giyen, öz bakımı yerinde olan, yürürken ve otururken zorlanan bu sebeple oturmaktan kaçınan bir kız çocuktu. Yavaş hareket ettiği, göz temasından kaçındığ 1 ve konuşmasının yavaş ve alçak ses tonunda olduğu tespit edildi. Yönlendirilmiş ve sürdürülebilir dikkati doğaldı. Düşünce içeriğinde sol bacağının kısa kalması ve diş görünüşü ile ilgili kaygıları, yalnızlı, beğenilmeme gibi düşünceleri, hastalığ 1 ile ilgili inkar ve sorgulamaları, kendine zarar verme düşünceleri olduğu saptandı. Duygu durumu depresif ve kaygill, duygulanımı düşünce içeriği ile uyumlu idi. Algı bozukluğu saptanmadi.

\section{Klinik izlem:}

Klinik görüşmeler sonunda depresyon ve anksiyete bozukluğu tanıları konan S'e Sertralin $50 \mathrm{mg} /$ gün başlandı. S ile haftalık görüşmeler planlandı. $\mathrm{Bu}$ görüşmelerde $\mathrm{S}$ 'in yaşadığı travmatik deneyimler, aile ilişkileri ve aile bireyleriyle ilgili duyguları konusundaki farkındalığının arttırılması, kendi güçlü yönlerini fark etmesi, hastalığının iyileşme aşamalarında kontrol duygusunu geliştirebilmesi, kızgınlık, öfke, suçluluk gibi duygu ve tepkilerini ifade edebilmesi, hastalıkla ilgili düşüncelerini anlatabilmesi, sosyal uyumunu sağlayarak yaşam kalitesinin arttırılması, S ile aile ve sosyal etkileşim alanları arasındaki etkileşimin güçlendirilmesi amaçland1.

İzlem sürecinde bacağında fixatör olmas1 nedeniyle okula gitmek istemeyen $S$ 'in öğretmenleri ile görüşüldü, günlük olarak derslerini alması planlandı, S'in sınav günleri okula gitmesi sağlandi. S, hastane sürecinde arkadaşlarının kendisini aramamasından ve ziyarete gelmemelerinden dolay1 onlara kırgındı. Arkadaş ilişkileri gözden geçirildi ve onlarla etkinlikler planlandı. Keman ve yan flüt çalmayı çok seven, ancak hastalığ1 nedeniyle daha önce zevk aldığı bütün faaliyetlerden uzaklaşan $\mathrm{S}$ bu konuda desteklendi, tekrar keman ve yan flüt çalmaya başlaması sağlandı. Annenin S'in hastalığı ile ilgili kaygıları çok yoğundu, S'in "normal yaşama" uyum ve okul yaşantısına geri dönmesi ile ilgili güçlükler yaşamakta, aşırı korumacı tutumlar sergilemekteydi. Anne ile hastalığın aile bireyleri üzerindeki etkisi ve hastalık hakkında duygularını paylaşması desteklendi. İzlem sürecinde annenin kaygıları ile baş etmekte zorlanması, bu durumun S' in tedavi sürecini yavaşlatması nedeniyle anne bir erişkin psikiyatr tarafindan değerlendirmeye alındı ve anneye Essitalopram $10 \mathrm{mg}$ /gün başlandı. Anne, S'in hastalık sürecinde ayrılmış olduğu iş hayatına geri döndü. Süreç içinde S bir kez daha operasyon geçirdi, sol bacağındaki fixatör çıkarıldı, iki bacağı arasındaki uzunluk farkı $5 \mathrm{~cm}$ 'ye indi. $\mathrm{Bu}$ 
dönemde $\mathrm{S}$ ile görüşmelere ara verildi. Ameliyat sonrasında yürümesine izin verilmesi ile birlikte görüşmelere tekrar başland1. S, ilk 2 ay koltuk değnekleri ile yürümeye başladı, bu dönemde arkadaşlarının kendisini koltuk değnekleri ile görmesini istemediği için okula devam etmedi, ancak günlük olarak çalışması gereken konuları öğretmenlerinden öğrendi ve sınavlara dışarıdan katıldı. 2 ay sonunda $S$ koltuk değneklerini de bıraktı ve aktif olarak okul hayatına geri döndü.

Bir y1l süren görüşmeler sonunda $S$ 'in depresif belirtileri düzeldi ve medikal tedavisi sonlandırıldı. Aktif olarak okul yaşamına geri döndü ve arkadaş ilişkileri düzeldi. Dış görünüşü ile ilgili kaygıları azaldı, süreç içinde bir erkek arkadaşı oldu.

\section{Tartışma:}

Kanser tanısı hastalar için stres verici bir olaydır. Hastaların kansere yükledikleri anlamlar ve hastalığı anlayış biçimleri kansere verilen yanıtı etkilemektedir (7). Kanser tanıs1 öğrenildiğinden itibaren hem hasta hem de ailesi için birçok güçlügü beraberinde getirmektedir (8). Kanserde cerrahi tedavi sonucu dıştan görülen bir organın kayba uğramas1 ve beden görünümünün değişmesi hastalar için yıkıcı sonuçlara neden olabilmektedir (9). Hastalar yaşamlarını tehdit eden kanser tanısının yanı sıra, organ kaybının yol açtığ duygular ile de baş etmek durumunda kalmaktadirlar (10). Bu olguya 9 yaşında Ewing Sarkomu tanısı konulmuş, cerrahi tedavi ve kemoterapi uygulanmış, o dönemi hastanede yatarak geçirmiş ve sosyal ortamlardan izole olmuştur. Tekrarlayan cerrahi tedaviler nedeni ile sol bacağı sağ bacağına göre $10 \mathrm{~cm}$ daha kısa kalmıştır. Kanser tedavisi sonucunda beden görünümü değişmiştir. Bu durum olgunun beden algisında değişikliğe ve özgüveninde zedelenmeye yol açmış ve kızgınlık, dış görünüş ile ilgili kaygılarda artış ve beğenilmeme duyguları ile sonuçlanmıştır. Bunu da uygulanan cümle tamamlama testinde şu şekilde ifade etmiştir; "En çok utandığım şey yolda yürürken birinin bacağıma bakması".

Ergenlik çağında kişi nasıl göründüğüne, başkalarınca nasıl değerlendirildiğine büyük önem vermektedir. $\mathrm{Bu}$ dönemde fizik görünüm ile ilgili kusurlar abartılma eğilimindedir (11). Böyle önemli bir gelişimsel dönemde olgumuzun hayatı tehdit eden bir hastalık tanisı alması ve bu hastalık nedeniyle bedeninin bir bölümünün kaybına uğraması belirgin ruhsal bozulmaya yol açmış, ayrıca sosyal açıdan kendini kısıtlamasına neden olmuştur. Sosyal işlevsellikte düşme çocukluk ya da erişkin yaş dönemlerine göre ergen yaş grubunda daha fazla ruhsal bozulmaya neden olan bir durumdur. Özellikle ergenlik dönemindeki kızlarda depresif bozuklukların daha s1k görüldüğü bildirilmektedir (12). Olgumuz da değerlendirme sürecince Depresif Bozukluk

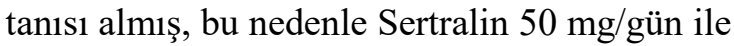
tedavisi düzenlenmiştir. Ayrıca, okul ile işbirliği içinde uygun düzenlemeler yapılmış, olguya sosyal ve eğitsel açıdan destek verilmiş, güçlü yönleri desteklenerek benlik saygısını yükseltmeyi ve sosyal girişkenliği sağlayıcı çalışmalar yapılmıştır.

Ergenlik döneminin diğer önemli gelişimsel özellikleri arasında otonomi kazanma ve bağımsızlık duygusu geliștirme, karşı cinsle yakın ilişkiler kurma ve gelecekle ilgili planlar yapma yer almaktadır. Hastalık nedeniyle ebeveynlere bağımlılığın artması ebeveynle ergenin ilișkisini zedeleyebilmektedir. $\mathrm{Bu}$ yaş döneminde eğitimle ilgili önemli kararların alınması ve birçok sınavın da bu dönemde yapılması nedeniyle gelecekle ilgili planlar hastalık nedeniyle olumsuz etkilenebilmektedir (13). Olgumuz hastalık nedeniyle uzun süreli ve ağır tedavi süreçlerinden geçmiş, bu süreçler boyunca da ailesinin yakın bakımına ihtiyaç duymuştur. Ailesini tanımlarken babasını ilgisiz ve ziyaretine gelmeyen biri olarak, annesini ise kendisine çok düşkün ancak oldukça endişeli biri olarak tanımlamıştır. Kanser tanısı olan çocuğun ebeveynlerinde çocuğun tedavisi süresince anksiyete, ambivalan duygular, depresif duygulanım, suçluluk duyguları görülebilmektedir. Çocuk veya gençlerin remisyon sonrası uzun dönem kontrollerinde bile ebeveynlerinde travma sonrası stres bozukluğu belirtileri bildirilmiştir (14). Genel olarak çocukluk çağı kanserlerine psikiyatrik yaklaşımda öncelikle hasta ile ailesinin anlaşılması büyük önem taşımaktadır. Anksiyeteyi azaltmak için hastanın ve ailenin bilgilendirilmesi, psikopatolojik tablolar ortaya çıktığında bunların zaman kaybetmeden tedavisi, aile içi duyguların konuşulmasının desteklenmesi, açık iletişimle birlikte umudun devamlılığının sağlanması gerekmektedir (15). Olgumuzda da depresyon ve anksiyete belirtilerinin yüksek düzeyde olmasının,

Adressforcorrespondence: Uzm. Dr. Nagihan Saday Duman. Bursa Sevket Yılmaz Eğitim ve Araștırma Hastanesi, Çocuk ve Ergen Ruh Sağlığı Birimi 06590 Bursa - Türkiye

e-mali: n_saday@hotmail.com

Available at www.actaoncologicaturcica.com

Copyright @Ankara Onkoloji Hastanesi 
annesinin hastalık ile ilgili yoğun kaygılarının olması ve çocuğuna olan aşırı bağlı özelliklerinin karşıllklı etkileşiminden kaynaklanabileceği düşünülmüştür. Annenin de psikoterapötik tedavi sürecine katılması, hastalıkla ilgili duygu ve düşüncelerinin çalışılması ve bireysel medikal tedavi almasının olgumuzun iyileşme sürecinde önemli bir katkısının olduğu düşünülmüştür.

\section{Sonuc}

Çocukluk çă̆ı kanserlerinden sağkalım oranlarının artması uzun süreli izlemde olguların yaşadığı fiziksel, duygusal, bilişsel ve sosyal destekle ilgili problemleri görünür hale getirmektedir. $\mathrm{Bu}$ süreçte sadece hasta çocuğu değil, tüm aileyi birlikte değerlendirmek ve desteklemek gerekmektedir. Sonuç olarak, bu olguların uzun süreli izleminde çok yönlü psikoterapötik girișimlerin çocuk ve ailesinin hastalık ile baş edebilmesi ve sonraki süreçte normal yaşama dönebilmesi açısından önemli bir yeri vardır.

\section{Çıkar Çatışması: Yok}

\section{Kaynaklar}

1) Boyle P, Levin B. Dünya Kanser Raporu. Lyon, Uluslararası Kanser Araştırmaları Kurumu, 2008.

2) Robison LL. The Childhood Cancer Survivor Study: a resource for research of long-term outcomes among adult survivors of childhood cancer. Minn Med, 2005;88(4):4549.

3) Bhatia S, Landier W. Evaluating survivors of pediatric cancer. Cancer J, 2005;11(4):340-354.

4) Özbaran B, Erermiş S. Kanser tedavisi gören çocuk ve gençlerde uzun süreli izlem sürecinde psikososyal özelliklerin tanımlanması ve genel yaklaşım ilkeleri. Klinik Psikiyatri, 2006;9:185-190.

5) Barakat L, Kazak A, Meadows AT ve ark. Families surviving childhood cancer: a comparison of posttraumatic stres symptoms with families of healthy children. J. Pediatr Psychol, 1997;22:843-859.

6) Yeh $\mathrm{CH}$, Wang YF. Competence of and emotional/behavioral problems in pediatric oncology patients in Taiwan. Cancer Nurs, 2004;27(5):413-22.

7) Ateşçi FÇ, Oğuzhanoğlu NK, Baltalarlı B, Karadağ F, Özdel O, Karagöz N. Kanser hastalarında psikiyatrik bozukluklar ve ilişkili etmenler. Türk Psikiyatri Dergisi, 2003;14(2): 145-152.

8) Gümüs AB. Meme kanserinde psikososyal sorunlar ve destekleyici girişimler. Meme sağlı̆̆ 1 dergisi, 2006;2(3):108-113.

9) Arıkan RN. Travmatik bir yaşantı: meme kanseri ve mastektomi. Kriz dergisi, 2000;9(1);39-46.

10) Karamanoğlu Yavuz A, Gök Özer F. Mastektomili hastalarda evde bakım. Meme Sağlığı Dergisi, 2008;4(1):3-8.
11) Çok F. Body image satisfaction in Turkish adolescents. Adolescence, 1990;98:409-13.

12) Spirito A, deLawyer DD, Stark U. Peer relations and social adjustment of chronically ill children and adolescents. Clin Psychol Rev. 1991;11:539-64.

13) Yağc1-Küpeli B, Küpeli S. Çocukluk çağı kanserleri ve yaşam kalitesi. Archives Medical Review Journal. 2015;24(3);368-89.

14) Langeveld NE, Grootenhuis MA, Voute PA ve ark. Posttraumatic stres symptoms in adult survivors of childhood cancer. Pediatr Blood Cancer, 2004;42(7):604610.

15) Van Dongen-Melman JE. Information booklet for parents of children surviving cancer. Leukemia, 1997;11(11):1799-806. 